\title{
HERPES VIRUS, HUMAN PAPILLOMA VIRUS AND POLYOMAVIRUS INFECTION IN PATIENTS UNDERGOING BIOLOGICAL THERAPY
}

\author{
Ramona Stefania Popescu ${ }^{1,2}$, Oana Sandulescu ${ }^{1,2}$, Andra Balanescu ${ }^{1,3}$, Mihaela Radulescu ${ }^{1,2}$, \\ Ruxandra Ionescu ${ }^{1,3}$, Adrian Streinu-Cercel ${ }^{1,2}$ \\ ${ }^{1}$ Carol Davila University of Medicine and Pharmacy, Bucharest, Romania \\ ${ }^{2}$ Prof. Dr. Matei Bals National Institute for Infectious Diseases, Bucharest, Romania \\ ${ }^{3}$ Internal Medicine and Rheumatology Clinic, Sf. Maria Hospital, Bucharest, Romania
}

\begin{abstract}
Biological therapy has redesigned the treatment of certain systemic inflammatory disorders, and it is currently employed in clinical practice by specialties such as rheumatology, dermatology, gastroenterology, neurology and oncology.

A decade's worth of data has classified biological therapy as safe and effective for the treatment of a large number of diseases. However, its associated risk of secondary infections remains a major issue, particularly when discussing long-term immunosuppressive treatment. Secondary viral infections can require delaying or discontinuing biological therapy, thus leading to a relapse or reactivation of the underlying disorder, and this can happen in patients with already limited therapeutic options.

Thorough screening and timely diagnosis of viral reactivations are necessary in order to maximize the benefits and reduce the risks associated with biological therapy. Viruses frequently associated with such reactivations include hepatitis B and C viruses, cytomegalovirus, varicella-zoster virus, and Epstein-Barr virus. This review focuses on the risk of reactivation associated with biological therapy in patients with autoimmune diseases and underlying herpes virus, human papilloma virus and polyomavirus infections.
\end{abstract}

Keywords: biological therapy, viral infections, herpes virus, human papilloma virus, polyomavirus

\section{BACKGROUND}

Biological therapy has become the cornerstone for the treatment of many autoimmune conditions and malignancies. Biologics are immunomodulator agents (antibodies or other peptides) that interfere with the regular humoral immune response. Thus, in addition to beneficial effects in relation with the underlying disease, biological therapy also leaves the patient more susceptible to infection by inducing a certain degree of immunosuppression.

Well-known complications of this type of therapy include increased rates of bacterial and mycobacterial infections (1), as well as opportunistic infections with Pneumocystis jiroveci $(2)$ or fungi $(3,4)$. However, there is less standardized information available to describe the potential risk associated with reactivation of pathogenic viruses that remain latent in the host following primary infection. Reactivation occurs through a switch from latency to lytic replication (5), a process that may be triggered by various stimuli, including immunosuppression associated with biological therapy. The viruses frequently incriminated in reactivation under biological therapy include hepatitis B (6) or C (7) viruses, cytomegalovirus, varicella-zoster virus and Epstein-Barr virus.

This review focuses on the risk of reactivation associated with biological therapy in patients with autoimmune diseases and underlying herpes virus, human papilloma virus and polyomavirus infections.

\section{Herpes simplex virus}

Herpes simplex viruses (HSV) are part of the $\mathrm{Al}$ phaherpesvirinae subfamily. A correct diagnosis of $\mathrm{HSV}$ infection requires a polymerase chain reaction

Correspondence address:

Ramona Stefania Popescu, Prof. Dr. Matei Bals National Institute for Infectious Diseases, 1 Dr. Calistrat Grozovici St., Bucharest, Romania E-mail: ramona.stefania.popescu@gmail.com 
(PCR) on tissue or bodily fluid samples (8). HSV-1 and HSV-2 have the capacity to establish latency in sensitive neurons (9), such as the dorsal root ganglia, or trigeminal ganglia $(10,11)$. HSV-1 latency has also been described in corneal tissue, its reactivation leading to herpetic keratitis (10), or in sympathetic thoracic ganglia (12).

The reactivation of herpes simplex viruses has been correlated with the use of rituximab, mainly in oncologic patients (13). Cornely et al. (14) have reviewed 992 patients receiving alemtuzumab, rituximab or both, and have identified a total of 299 (30.1\%) opportunistic infections; of these, 30 (10\%) cases represented HSV reactivations.

The field literature also reports isolated cases of herpetic encephalitis after therapy with anti-tumor necrosis factor (TNF)- $\alpha$ agents $(15,16)$, and Justice et al. (17) have described a case of disseminated cutaneous HSV-1 infection in a patient with rheumatoid arthritis (RA) undergoing therapy with infliximab.

Acyclovir, valacyclovir or famciclovir can be used to treat acute or recurrent infection. The use of anti-TNF agents is not recommended during acute infection, due to an increase in the risk of dissemination (18). In patients with severe HSV infection, immunosuppressive therapy needs to be discontinued (19).

\section{Varicella-zoster virus}

Varicella-zoster virus is associated with two distinct clinical outlines: varicella (chickenpox) and herpes zoster (HZ, otherwise known as shingles). Varicella is the primary infection with VZV that commonly displays a benign, self-limiting evolution, particularly in childhood (20). The reactivation of the latent virus leads to herpes zoster and generally occurs during immune-depression $(21,22)$, presenting as unilateral blistering rash, with dermatomal distribution, and often leading to complications such as chronic pain or post herpetic neuralgia (23).

VZV establishes latency reservoirs in dorsal root spinal ganglia and in cranial nerve ganglia (24). The latent virus has also been identified in the autonomic nervous system (25), particularly in sympathetic thoracic ganglia (12), or in neurons of the enteric nervous system (24).

In patients receiving treatment with anti-TNF- $\alpha$ agents, herpes zoster can present an atypical clinical picture, either disseminated (26) or mimicking other infections (27); a multi-dermatomal outline with multiple recurrences has also been described (28). Moreover, VZV reactivation has also been associated with encephalitis (29) or vasculopathy (30), with unfavorable and potentially fatal evolution.

Recent studies have shown that the risk of $\mathrm{HZ}$ significantly increases with old age, treatment with corticosteroids and a combination of anti-TNF- $\alpha$ and conventional disease-modifying antirheumatic drugs (c-DMARDs) (31). The incidence of $\mathrm{HZ}$ in patients undergoing treatment with anti-TNF- $\alpha$ is three-fold higher compared to the general population (32), the lowest risk being associated with adalimumab, and the highest one, with infliximab, according to the study performed by Galloway et al. (33) on the British Society for Rheumatology Biologics Register (BSRBR) cohort. Cases of HZ associated with tocilizumab (34-36) or rituximab (37) have also been reported.

The live attenuated shingles vaccine is recommended for prophylaxis of $\mathrm{HZ}$ in immunocompetent patients over 60 years of age (38). Published studies have reported a reduction in the risk of $\mathrm{HZ}$ with up to $70 \%$ in immunocompetent persons over 50 years of age (39). Despite of the fact that the HZ risk is 1.5 to 2 times higher in patients with immune-mediated diseases such as RA or Crohn's disease $(40,41)$, the US Food and Drug Administration (FDA), the Advisory Committee on Immunization Practices (ACIP) and the American College of Rheumatology (ACR) do not recommend the administration of the shingles vaccine during treatment with biologics (42) due to safety issues, namely the risk of acute post-vaccination VZV infection. The vaccine can, however, be administered in these patients with a minimum of 3 weeks prior to initiating biological therapy, this timespan representing the incubation period for VZV.

A retrospective cohort study of 463,541 patients with ages above 60 years, with RA, psoriasis, psoriatic arthritis, ankylosing spondylitis or inflammatory bowel disease and enrolled in the Medicare social insurance system, has reported that the administration of the shingles vaccine was not associated with an increase in the incidence of herpes zoster immediately post-vaccination in patients undergoing treatment with biologics; furthermore, vaccination lead to a significant long term reduction in the risk of $\mathrm{HZ}$ in these patients (38).

In acute VZV infection biological therapy needs to be discontinued until all vesicles have cleared out, 
and antivirals such as acyclovir, valacyclovir, famciclovir or foscarnet can be administered in selected cases (43).

\section{Epstein-Barr virus}

The Epstein-Barr virus (EBV) is part of the Gammaherpesvirinae subfamily, and it presents a particular tropism for B cells. The virus is ubiquitous, and over $90 \%$ of the general population has a positive serology for EBV (44). Infectious mononucleosis is the acute infection (45), when the virus establishes a cellular latency reservoir, its genome changing its shape to become circular, episomal, embedded in the nucleus of memory B cells (44). Apart from the welldescribed latency in B cells, recent laboratory studies have reported EBV-2 latency in T cells (46).

EBV latency has been associated with multiple neoplastic disorders (Burkitt lymphoma, nasopharyngeal carcinoma of lymphoproliferative disorders) as well as autoimmune diseases (47-49), being a potential trigger for RA $(50,51)$.

The incidence of lymphoma in patients with RA is twice as high compared to the general population (52). It is currently unclear whether treatment with anti-TNF- $\alpha$ additionally increases this risk through reactivation of latent $\mathrm{EBV}$ infection.

Balandraud et al. (53) have reported that patients with RA display EBV peripheral blood mononuclear cells viremia (16 copies/500 ng DNA) 10 times higher than the control group, this increase being directly correlated to disease activity. Follow-up data for over 4 years has shown that treatment with antiTNF- $\alpha$ agents (infliximab or etanercept) does not significantly influence viral load. Askling et al. (54), after analyzing 6,604 patients from the Swedish Biologics Register (ARTIS), concluded that TNF antagonists do not influence the incidence of lymphoma in patients with RA.

However, a different study showed that viral load monitoring could select patients susceptible to developing lymphoma, with values above 500 copies/500 ng DNA pointing to potential evolution towards lymphoproliferative disease (52). Park et al. (55) have described a case of diffuse lymphoproliferative disease associated with EBV infection, that developed shortly after the initiation of etanercept treatment in a patient with RA, and that regressed spontaneously after discontinuation of biological therapy.

Colaci et al. (56) report reactivation of EBV infection in a patient with RA, 11 days after the first dose of infliximab, with spontaneous remission of symptoms over the course of 5 days; in this case treatment was continued after a time span of 4 weeks, without further events. Ueda et al. (57) describe EBV reactivation leading to acute disseminated encephalomyelitis in a patient receiving infliximab for Crohn's disease.

Acute EBV infection does not require specific antiviral treatment due to its self-limiting evolution (58); antivirals such as acyclovir or ganciclovir can be used in cases with severe outlines (18). Discontinuing anti-TNF agents should be considered in severe cases of EBV-associated illness (18).

There is no currently approved vaccine against $\mathrm{EBV}$, but there is dire need for developing one, since this particular virus is linked to 200,000 new cases of neoplastic disease each year (59).

\section{Cytomegalovirus}

Cytomegalovirus (CMV) is a common pathogen belonging to the Betaherpesvirinae subfamily and is transmitted by direct contact with bodily fluids.

Seroprevalence studies suggest that by the time they reach adolescence, $10-20 \%$ of the population has already been exposed to CMV infection, the percentage increasing to $40-100 \%$ in adult population (18).

The primary infection in immunocompetent patients is commonly asymptomatic, but it can also display a mononucleosis-like outline, with the virus subsequently remaining latent in $\mathrm{CD} 34+$ progenitor myeloid cells (60) and in monocytes/macrophages (61). CMV persistence has also been associated with immunosenescence (62).

Reactivation of latent infection in immunosuppressed patients can virtually affect any system of the human body, with frequent case reports of encephalitis, pneumonia, enterocolitis, hepatitis or retinitis in HIV-positive patients $(18,60)$. CMV has also been incriminated as potential trigger in autoimmune diseases (60) such as systemic lupus erythematosus (SLE) and RA.

CMV infection reactivation in patients undergoing anti-TNF- $\alpha$ therapy has been documented in a series of case reports (63-65). Petersen et al. (65) describe 2 cases of CMV infection secondary to etanercept and efalizumab therapy, respectively. Both cases were characterized by a prolonged evolution, with complains of severe fatigue in addition to other symptoms. Le Clech et al. (66) present a case of se- 
vere CMV infection in a patient with cancer undergoing maintenance treatment with rituximab.

However, the study performed by Davignon et al. (67) showed that the CD4+ T cell response to CMV is not influenced by treatment with anti-TNF- $\alpha$ agents and that the infection remains under control even in patients with RA undergoing anti-TNF- $\alpha$ therapy. Torre-Cisneros et al. (68) prospectively followed 15 patients with RA treated with infliximab, over the course of the first 6 weeks of therapy, with the purpose of evaluating the reactivation of $\mathrm{CMV}$, EBV or human herpes viruses (HHV) 6, 7 and 8. No signs of reactivation or primary infection were detected in this study.

Patients that are asymptomatic or display mild disease do not require specific therapy and do not present a contraindication for continuing the antiTNF treatment. In severe cases however, biological therapy should be discontinued until symptoms' resolution and antiviral therapy should be considered (18). Therapeutic options include ganciclovir, and valganciclovir or foscarnet in case of resistance or intolerance to ganciclovir (18).

\section{Human herpes virus 8}

Human herpes virus 8 (also known as Kaposi's sarcoma-associated herpes virus - KSHV) belongs to the subfamily Gammaherpesvirinae and represents the infectious agent underlying Kaposi's disease (KD) and other lymphoproliferative diseases such as primary effusion lymphomas and multicentric Castelman's disease (69). This is why the virus is also named Kaposi's Sarcoma-Associated Herpes virus (KSHV) $(70,71)$.

The exact transmission routes for HHV-8 are not fully understood. Both sexual and non-sexual transmission has been described (69), HHV-8 having been detected in saliva, prostatic fluid, blood products or transplanted organs (70). Latency is established through a dramatic change in the viral genome, from an initial histone-free outline, to a multi-copy histone-packed episomal chromatin structure (72), circularized and tethered to host chromosomes by the viral latency-associated nuclear antigen (LANA) (73). LANA also facilitates latency and stimulates the proliferation of latently-infected cells through an upregulation of survivin, an inhibitor of apoptosis (74). Viral infection of endothelial cells is associated with $\mathrm{KD}$, while infection of $\mathrm{B}$ cells is linked to the above-referenced lymphoproliferative disorders (70).
Unlike EBV and CMV, two other viruses belonging to the Herpesviridae family, HHV-8 does not seem to be involved in the pathogenesis of autoimmune diseases and does not represent a possible trigger for such conditions (75).

Although HHV-8 infection represents a trigger for $\mathrm{KD}$, other co-factors are also needed, namely immunosuppression secondary to HIV infection or post-organ transplant (76). KD can also be observed in elderly persons without other apparent causes of immunodepression.

Field literature data is scarce and cannot support the role of biological therapy in the reactivation of latent infection with HHV-8.

Lavagna et al. (77), having prospectively followed for 14 weeks 60 patients with Crohn's disease undergoing treatment with infliximab, have not recorded any cases of reactivation of HHV-8 infection. Nicoli et al. (78) present safety and efficacy data for rituximab in the treatment of multicentric Castelman disease. Other case reports describe the use of tocilizumab in the treatment of iatrogenic KD in a patient with RA (79), or in treatment of multicentric Castelman disease (80).

On the other hand, field literature describes cases of KD secondary to infliximab (81), adalimumab (82) or rituximab $(59,83)$ treatment. Martinez et al. (84) report a KD case that started 10 days after the second dose of infliximab in an HIV-negative patient with corticodependent Crohn's disease; following discontinuation of infliximab, an improvement in KD skin lesions was observed.

\section{Human papilloma virus}

Human papilloma virus (HPV) belongs to the Papillomaviridae family and is a sexually transmitted virus. Most infections with HPV are subclinical (85), and $80 \%$ of cases display a self-limiting evolution within one year, as a result of cellular immune response (86). Several viral subtypes have been identified, with different clinical evolution. For example, subtypes 1, 2, 4, 6, and 11 are associated with low risk of malignant transformation, causing benign cutaneous warts or condyloma acuminata, while subtypes $16,18,30,31$ are associated with cervical dysplasia, cervical cancer, and rectal, penile, vulvar, vaginal or oropharyngeal carcinoma (18).

So far, the exact mechanisms whereby HPV establishes latency reservoirs have not been identified, 
but one hypothesis describes viral latency in basal epithelial stem cells, whose binary division leaves a copy of the virus-infected cell in the basal layer, while the daughter-cell undergoes terminal differentiation (87). Maglennon et al. (88) also describe the phenomenon of immune-mediated latency in epithelial cells that do not sustain the complete virus life cycle.

At the moment, there is very little data on the incidence and prevalence of HPV infection in patients with rheumatic conditions, despite the fact that HPV infection is the most frequent sexually-transmitted disease in the United States $(85,86)$.

A recent study by Waisberg et al. (89) evaluated HPV and Chlamydia trachomatis infections in patients with RA pre- and post- anti-TNF- $\alpha$ therapy, and concluded that in the short term this treatment does not appear to increase the risk of HPV infection evolution in this category of patients. However, Georgala et al. (90) reported a potential association between anti-TNF- $\alpha$ agents and progression of HPV infection by describing 3 cases with fast progression of cytological lesions; for this reason they recommend a routine Pap smear, before, during and after treatment.

In conclusion, although limited, literature data indicate a possible association between immunosuppressive therapy and persistent HPV infection with a risk of progression towards a neoplastic pathology. Future studies are needed to determine the optimal screening strategy for HPV infection before starting biological therapy, and to evaluate the benefit of anti-HPV vaccination in immunosuppressed patients (85).

\section{Polyomavirus - JC}

$\mathrm{JC}$ virus (JCV) is a DNA virus, part of the Polyomaviridae genus, Papovaviridae family (91). Primary infection takes place early during childhood by respiratory or urinary-oral transmission and is asymptomatic (92). The main latency reservoir for the circular episomal form of JCV is represented by renal epithelial cells (93) and urothelial cells, however, there are clues as to the latency or persistence of the virus in B lymphocytes, spleen (94), tonsils (95), lymph nodes (96), or bone marrow (97). The two main pathologies determined by the reactivation of JCV include polyomavirus-associated nephropathy (particularly in patients with kidney or other organ post-transplant status) (94) and progressive multifo- cal leukoencephalitis (PML), a rare and usually fatal condition of the central nervous system, which requires the reactivation of JCV with neuroadaptation (95) leading to viral cytolytic replication in oligodendrocytes, thereby determining multiple demyelination foci (98).

Even though most cases of PML have been described in patients with severe immunosuppression, such as AIDS stage HIV infection, neoplasia or postorgan transplant (92), the association between this condition and biological therapy has become widely known after several PML cases were reported in patients who received natalizumab, a monoclonal antibody directed against $\alpha 4$ integrin, that is used in the treatment of multiple sclerosis (99) and Crohn's disease (100). Another biologic agent that has been associated with this pathology is efalizumab (used in the treatment of psoriasis) (101).

The use of biological therapy in rheumatic conditions has led to the reporting of such reactivation cases in patients with RA or SLE under treatment with monoclonal antibodies such as rituximab (102106) or tocilizumab (107).

A retrospective cohort study that included 734 patients with inflammatory bowel disease undergoing treatment with infliximab has described a fatal case of PML after use of natalizumab and infliximab (108). Also, Yamamoto et al. (109) have reported a case of PML in a patient with RA under treatment with etanercept; even though this patient exhibited characteristic symptoms for PML, PCR for JCV DNA in the cerebrospinal fluid was negative.

In conclusion, PML is a rare complication with unfavorable prognosis. Because the diagnosis of PML is hard to establish and the most important therapeutic intervention requires reduction of immunosuppression status (110), this etiology has to be considered in any immunosuppressed patient who develops new neurologic symptoms such as disorientation, ataxia, speech disorders or vision impairment (85).

\section{CONCLUSIONS}

Patients undergoing treatment with the currently available biologics are at high risk for reactivation of latent viral infections. Such patients should therefore undergo thorough screening prior to the initiation of therapy, including checking and updating the patients' vaccination status. If found positive for latent viral infections, these patients might benefit from prophylactic antiviral therapy. Clinicians monitoring 
patients in treatment with biologics should be aware that viral infections may display an atypical presentation. Currently available literature data is scarce, and does not present sufficient information derived from comparative studies, in order to determine the best choice of biologics from an infectious risk perspective.
Acknowledgement: This paper is partially supported by the Sectoral Operational Programme Human Resources Development (SOP HRD), financed from the European Social Fund and by the Romanian Government under the contract number POSDRU/159/1.5/S/ 137390.

\section{REFERENCES}

1. Yoo I.K., Choung R.S., Hyun J.J., Kim S.Y., Jung S.W., Koo J.S., et al. Incidences of serious infections and tuberculosis among patients receiving anti-tumor necrosis factor-alpha therapy. Yonsei medical journal. 2014; 55(2):442-8.

2. Desales A.L., Mendez-Navarro J., Mendez-Tovar L.J., OrtizOlvera N.X., Cullen G., Ocampo J., et al. Pneumocystosis in a patient with Crohn's disease treated with combination therapy with adalimumab. Journal of Crohn's \& colitis. 2012; 6(4):483-7.

3. Takazono T., Izumikawa K., Yoshioka S., Matsuo N., Yamakawa M., Suyama N., et al. Possible pulmonary cryptococcosis in a patient with Crohn's disease during anti-tumor necrosis factor-alpha treatment: a case report and literature review. Japanese journal of infectious diseases. 2012; 65(5):461-4.

4. Pinheiro Bdo V., Delgado Ade A., Chebli J.M. Hepatitis and pneumonitis during adalimumab therapy in Crohn disease: mind the histoplasmosis! Arquivos de gastroenterologia. 2014; 51(1):73-6.

5. Traylen C.M., Patel H.R., Fondaw W., Mahatme S., Williams J.F., Walker L.R., et al. Virus reactivation: a panoramic view in human infections. Future virology. 2011; 6(4):451-63.

6. Kim H.Y., Kim W. Chemotherapy-related reactivation of hepatitis B infection: updates in 2013. World J Gastroenterol. 2014; 20(40):14581-8

7. Zuckerman E. Vital hepatitis reactivation with anti-tumor necrosis factor-alpha: what do we know? The Israel Medical Association journal: IMAJ. 2013; 15(6):298-300.

8. Shenoy E.S., Mylonakis E., Hurtado R.M., Venna N. Natalizumab and HSV meningitis. J Neurovirol. 2011; 17(3):288-90.

9. Ma J.Z., Russell T.A., Spelman T., Carbone F.R., Tscharke D.C. Lytic gene expression is frequent in HSV-1 latent infection and correlates with the engagement of a cell-intrinsic transcriptional response. PLoS Pathog. 2014; 10(7):e1004237.

10. Higaki S., Fukuda M., Shimomura Y. Virological and molecular biological evidence supporting herpes simplex virus type 1 corneal latency. Jpn J Ophthalmol. 2015; 59(2):131-4.

11. Messer H.G., Jacobs D., Dhummakupt A., Bloom D.C. Inhibition of H3K27me3-Specific Histone Demethylases JMJD3 and UTX Blocks Reactivation of Herpes Simplex Virus 1 in Trigeminal Ganglion Neurons. J Virol. 2015; 89(6):3417-20.

12. Nagel M.A., Rempel A., Huntington J., Kim F., Choe A., Gilden D. Frequency and abundance of alphaherpesvirus DNA in human thoracic sympathetic ganglia. J Virol. 2014; 88(14):8189-92.

13. T.K., Daikos G., Boumpas D., Tsiodras S. Does rituximab increase the incidence of infectious complications? A narrative review. Int J Infect Dis. 2011; 15(1):e2-16.

14. Cornely O.A., Ullmann A.J., Karthaus M. [Opportunistic infections after treatment with monoclonal antibodies]. Wien Med Wochenschr. 2004; 154(9-10):209-17.

15. Bradford R.D., Pettit A.C., Wright P.W., Mulligan M.J., Moreland L.W., McLain D.A., et al. Herpes simplex encephalitis during treatment with tumor necrosis factor-alpha inhibitors. Clin Infect Dis. 2009; 49(6):924-7.

16. Crusio R.H., Singson S.V., Haroun F., Mehta H.H., Parenti D.M. Herpes simplex virus encephalitis during treatment with etanercept. Scand J Infect Dis. 2014; 46(2):152-4.

17. Justice E.A., Khan S.Y., Logan S., Jobanputra P. Disseminated cutaneous Herpes Simplex Virus-1 in a woman with rheumatoid arthritis receiving infliximab: a case report. J Med Case Rep. 2008; 2:282.

18. Ali T., Kaitha S., Mahmood S., Ftesi A., Stone J., Bronze M.S. Clinical use of anti-TNF therapy and increased risk of infections. Drug Healthc Patient Saf. 2013; 5:79-99.

19. Domm S., Cinatl J., Mrowietz U. The impact of treatment with tumour necrosis factor-alpha antagonists on the course of chronic viral infections: a review of the literature. $\mathrm{Br} J$ Dermatol. 2008; 159(6):1217-28.

20. Shrivastava S.R., Shrivastava P.S., Ramasamy J. Epidemiological investigation of a case of chickenpox in a medical college in Kancheepuram, India. Germs. 2013; 3(1):18-20.

21. Schmader K., Gnann J.W., Jr., Watson C.P. The epidemiological, clinical, and pathological rationale for the herpes zoster vaccine. J Infect Dis. 2008; 197 Suppl 2:S207-15.

22. Sampathkumar P., Drage L.A., Martin D.P. Herpes zoster (shingles) and postherpetic neuralgia. Mayo Clin Proc. 2009; 84(3):274-80.

23. Mueller N.H., Gilden D.H., Cohrs R.J., Mahalingam R., Nagel M.A. Varicella zoster virus infection: clinical features, molecular pathogenesis of disease, and latency. Neurol Clin. 2008; 26(3):675-97, viii.

24. Gershon A.A., Chen J., Davis L., Krinsky C., Cowles R., Reichard R., et al. Latency of varicella zoster virus in dorsal root, cranial, and enteric ganglia in vaccinated children. Trans Am Clin Climatol Assoc. 2012; 123:17-33; discussion -5.

25. Gilden D., Mahalingam R., Nagel M.A., Pugazhenthi S., Cohrs R.J. Review: The neurobiology of varicella zoster virus infection. Neuropathol Appl Neurobiol. 2011; 37(5):441-63.

26. Choi H.J., Kim M.Y., Kim H.O., Park Y.M. An atypical varicella exanthem associated with the use of infliximab. Int J Dermatol. 2006; 45(8):999-1000

27. Tresch S., Trueb R.M., Kamarachev J., French L.E., Hofbauer G.F. Disseminated herpes zoster mimicking rheumatoid vasculitis in a rheumatoid arthritis patient on etanercept. Dermatology. 2009; 219(4):347-9

28. Strangfeld A., Listing J., Herzer P., Liebhaber A., Rockwitz K., Richter C., et al. Risk of herpes zoster in patients with rheumatoid arthritis treated with anti-TNF-alpha agents. Jama. 2009; 301(7):737-44.

29. Buccoliero G., Lonero G., Romanelli C., Loperfido P., Resta F. Varicella zoster virus encephalitis during treatment with anti-tumor necrosis factor-alpha agent in a psoriatic arthritis patient. New Microbiol. 2010; 33(3):271-4.

30. Baek W., Lee S.G., Kim Y.S., Kim J.H., Jun J.B., Kim H.Y. Fatal varicella-zoster virus vasculopathy associated with adalimumab therapy. Arch Neurol. 2012; 69(9):1193-6.

31. Zisman D., Bitterman H., Shalom G., Feldhamer I., Comanesther D., Batat E., et al. Psoriatic arthritis treatment and the risk of herpes zoster. Ann Rheum Dis. 2014.

32. Di Costanzo L., Ayala F., Megna M., Gaudiello F., Patri A., Balato N. The risk of herpes zoster in the anti-TNF-alpha era: a case report and review of the literature. J Dermatol Case Rep. 2013; 7(1):1-4.

33. Galloway J.B., Mercer L.K., Moseley A., Dixon W.G., Ustianowski A.P., Helbert M., et al. Risk of skin and soft tissue infections (including shingles) in patients exposed to anti- 
tumour necrosis factor therapy: results from the British Society for Rheumatology Biologics Register. Ann Rheum Dis. 2013 72(2):229-34.

34. Mimata Y., Akasaka T., Nakano R., Murata T., Kawashima M., Shimamura T. Ramsay Hunt syndrome associated with tocilizumab therapy in rheumatoid arthritis: a case report. Int J Rheum Dis. 2013; 16(3):367-8

35. Roux C., Breuil V., Albert C., Allam V., Grisot C., Chami H., et al. Ophthalmic herpes zoster infection in patients with rheumatoid arthritis who were treated with tocilizumab. J Rheumatol. 2011; 38(2):399.

36. Kubandova Z., Mathieu S., Pourtier C., Soubrier M. Serious herpes zoster in rheumatoid arthritis under anti-interleukin-6 receptor antibody. Joint Bone Spine. 2010; 77(6):623-4.

37. Mishra R., Singh V., Pritchard C.H. Safety of biologic agents after rituximab therapy in patients with rheumatoid arthritis. Rheumatol Int. 2011; 31(4):481-4

38. Zhang J., Xie F., Delzell E., Chen L., Winthrop K.L., Lewis J.D., et al. Association between vaccination for herpes zoster and risk of herpes zoster infection among older patients with selected immunemediated diseases. Jama. 2012; 308(1):43-9.

39. Schmader K.E., Levin M.J., Gnann J.W., Jr., McNeil S.A., Vesikari T., Betts R.F., et al. Efficacy, safety, and tolerability of herpes zoster vaccine in persons aged 50-59 years. Clin Infect Dis. 2012; 54(7):922-8

40. Gupta G., Lautenbach E., Lewis J.D. Incidence and risk factors for herpes zoster among patients with inflammatory bowel disease. Clin Gastroenterol Hepatol. 2006; 4(12):1483-90.

41. Smitten A.L., Choi H.K., Hochberg M.C., Suissa S., Simon T.A., Testa M.A., et al. The risk of herpes zoster in patients with rheumatoid arthritis in the United States and the United Kingdom. Arthritis Rheum. 2007; 57(8):1431-8.

42. Singh J.A., Furst D.E., Bharat A., Curtis J.R., Kavanaugh A.F., Kremer J.M., et al. 2012 update of the 2008 American College of Rheumatology recommendations for the use of disease-modifying antirheumatic drugs and biologic agents in the treatment of rheumatoid arthritis. Arthritis Care Res (Hoboken). 2012; 64(5):625-39.

43. Arvin A.M. Varicella-zoster virus. Clin Microbiol Rev. 1996; 9(3):361-81.

44. Ok C.Y., Li L., Young K.H. EBV-driven B-cell lymphoproliferative disorders: from biology, classification and differential diagnosis to clinical management. Exp Mol Med. 2015; 47:e132.

45. Solomons H.D. Infectious mononucleosis or glandular fever revisited. Germs. 2012; 2(4):148

46. Coleman C.B., Wohlford E.M., Smith N.A., King C.A, Ritchie J.A., Baresel P.C., et al. Epstein-barr virus type 2 latently infects $T$ cells, inducing an atypical activation characterized by expression of lymphotactic cytokines. J Virol. 2015; 89(4):2301-12.

47. Angelini D.F., Serafini B., Piras E., Severa M., Coccia E.M., Rosicarelli B., et al. Increased CD8+ T cell response to EpsteinBarr virus lytic antigens in the active phase of multiple sclerosis. PLoS Pathog. 2013; 9(4):e1003220.

48. Lossius A., Johansen J.N., Torkildsen O., Vartdal F., Holmoy T. Epstein-Barr virus in systemic lupus erythematosus, rheumatoid arthritis and multiple sclerosis-association and causation. Viruses. 2012; 4(12):3701-30.

49. Draborg A.H., Jacobsen S., Westergaard M., Mortensen S., Larsen J.L., Houen G., et al. Reduced response to Epstein-Barr virus antigens by T-cells in systemic lupus erythematosus patients Lupus Sci Med. 2014; 1(1):e000015.

50. Lunemann J.D., Frey O., Eidner T., Baier M., Roberts S., Sashihara J., et al. Increased frequency of EBV-specific effector memory CD8+ T cells correlates with higher viral load in rheumatoid arthritis. J Immunol. 2008; 181(2):991-1000.

51. Brisslert M., Rehnberg M., Bokarewa M.I. Epstein-Barr virus infection transforms CD25+ B cells into antibody-secreting cells in rheumatoid arthritis patients. Immunology. 2013; 140(4):421-9.

52. Balandraud N, Roudier J, Roudier C. What are the links between Epstein-Barr virus, lymphoma, and tumor necrosis factor antagonism in rheumatoid arthritis? Semin Arthritis Rheum. 2005; 34(5 Suppl1):31-3.

53. Balandraud N., Meynard J.B., Auger I., Sovran H., Mugnier B., Reviron D., et al. Epstein-Barr virus load in the peripheral blood of patients with rheumatoid arthritis: accurate quantification using real-time polymerase chain reaction. Arthritis Rheum. 2003; 48(5):1223-8.

54. Askling J., Baecklund E., Granath F., Geborek P., Fored M., Backlin C., et al. Anti-tumour necrosis factor therapy in rheumatoid arthritis and risk of malignant lymphomas: relative risks and time trends in the Swedish Biologics Register. Ann Rheum Dis. 2009; 68(5):648-53.

55. Park S.H., Kim C.G., Kim J.Y., Choe J.Y. Spontaneous regression of EBV-associated diffuse lymphoproliferative disease in a patient with rheumatoid arthritis after discontinuation of etanercept treatment. Rheumatol Int. 2008; 28(5):475-7.

56. Colaci M., Sebastiani M., Sandri G., Meacci M., Ferri C. Epstein-barr virus reactivation after infliximab in rheumatoid arthritis: a case report. Case Rep Infect Dis. 2011; 2011:530568.

57. Ueda M., Tateishi T., Shigeto H., Yamasaki R., Ohyagi Y., Kira J. [A case of acute disseminated encephalomyelitis associated with Epstein-Barr virus reactivation during infliximab therapy]. Rinsho Shinkeigaku. 2010; 50(7):461-6.

58. Luzuriaga K., Sullivan J.L. Infectious mononucleosis. N Engl J Med. 2010; 362(21):1993-2000.

59. Aksoy S., Arslan C., Harputluoglu H., Dizdar O., Altundag K Malignancies after rituximab treatment: just coincidence or more? J Buon. 2011; 16(1):112-5.

60. Halenius A., Hengel H. Human cytomegalovirus and autoimmune disease. Biomed Res Int. 2014; 2014:472978.

61. Landais I., Nelson J.A. Functional genomics approaches to understand cytomegalovirus replication, latency and pathogenesis. Curr Opin Virol. 2013; 3(4):408-15

62. Sansoni P., Vescovini R., Fagnoni F.F., Akbar A., Arens R., Chiu Y.L., et al. New advances in CMV and immunosenescence. Exp Gerontol. 2014; 55:54-62.

63. Mizuta M., Schuster M.G. Cytomegalovirus hepatitis associated with use of anti-tumor necrosis factor-alpha antibody. Clin Infect Dis. 2005; 40(7):1071-2

64. Sari I., Birlik M., Gonen C., Akar S., Gurel D., Onen F., et al. Cytomegalovirus colitis in a patient with Behcet's disease receiving tumor necrosis factor alpha inhibitory treatment. World $\mathrm{J}$ Gastroenterol. 2008; 14(18):2912-4.

65. Petersen B., Lorentzen H. Cytomegalovirus complicating biological immunosuppressive therapy in two patients with psoriasis receiving treatment with etanercept or efalizumab. Acta Derm Venereol. 2008; 88(5):523-4.

66. Le Clech L., lanotto J.C., Quintin-Roue I., Tempescul A. Severe CMV complication following maintenance therapy with rituximab. BMJ Case Rep. 2013;2013.

67. Davignon J.L., Boyer J.F., Jamard B., Nigon D., Constantin A., Cantagrel A. Maintenance of cytomegalovirus-specific CD4pos T-cell response in rheumatoid arthritis patients receiving anti-tumor necrosis factor treatments. Arthritis Res Ther. 2010; 12(4):R142.

68. Torre-Cisneros J., Del Castillo M., Caston J.J., Castro M.C., Perez V., Collantes E. Infliximab does not activate replication of lymphotropic herpesviruses in patients with refractory rheumatoid arthritis. Rheumatology (Oxford). 2005; 44(9):1132-5.

69. Rohner E., Wyss N., Trelle S., Mbulaiteye S.M., Egger M., Novak U., et al. HHV-8 seroprevalence: a global view. Syst Rev. 2014; 3:11.

70. Giffin L., Damania B. KSHV: pathways to tumorigenesis and persistent infection. Adv Virus Res. 2014; 88:111-59.

71. Sofia Fernandes L. Human immunodeficiency virus and cancer. A population of HIV-infected patients at Hospital de Santa Maria and predictors of cancer. Germs. 2012; 2(2):60-74.

72. Campbell M., Kung H.J., Izumiya Y. Long non-coding RNA and epigenetic gene regulation of KSHV. Viruses. 2014; 6(11):4165-77.

73. Sun Q., Tsurimoto T., Juillard F., Li L., Li S., De Leon Vazquez E., et al. Kaposi's sarcoma-associated herpesvirus LANA recruits the DNA polymerase clamp loader to mediate efficient replication and virus persistence. Proceedings of the National Academy of Sciences of the United States of America. 2014; 111(32):11816-21.

74. Lu J., Jha H.C., Verma S.C., Sun Z., Banerjee S., Dzeng R., et al. Kaposi's sarcoma-associated herpesvirus-encoded LANA contributes to viral latent replication by activating phosphorylation of survivin. J Virol. 2014; 88(8):4204-17.

75. Balada E., Ramentol M., Felip L., Ordi-Ros J., SelvaO'Callaghan A., Simeon-Aznar C.P., et al. Prevalence of HHV-8 in systemic autoimmune diseases. J Clin Virol. 2015;62:84-8. 
76. Stiller C.A., Trama A., Brewster D.H., Verne J., Bouchardy C., Navarro C., et al. Descriptive epidemiology of Kaposi sarcoma in Europe. Report from the RARECARE project. Cancer Epidemiol. 2014; 38(6):670-8.

77. Lavagna A., Bergallo M., Daperno M., Sostegni R., Costa C., Leto R., et al. Infliximab and the risk of latent viruses reactivation in active Crohn's disease. Inflamm Bowel Dis. 2007; 13(7):896-902.

78. Nicoli P., Familiari U., Bosa M., Allice T., Mete F., Morotti A., et al. HHV8-positive, HIV-negative multicentric Castleman's disease: early and sustained complete remission with rituximab therapy without reactivation of Kaposi sarcoma. Int J Hematol. 2009; 90(3):392-6

79. Ingegnoli F., Tourlaki A., Gualtierotti R. Tocilizumab monotherapy in a patient with rheumatoid arthritis and iatrogenic Kaposi sarcoma. Clin Drug Investig. 2014; 34(2):159-61.

80. Nagao A., Nakazawa S., Hanabusa H. Short-term efficacy of the IL6 receptor antibody tocilizumab in patients with HIV-associated multicentric Castleman disease: report of two cases. J Hematol Oncol. 2014; 7:10

81. Ursini F., Naty S., Mazzei V., Spagnolo F., Grembiale R.D. Kaposi's sarcoma in a psoriatic arthritis patient treated with infliximab. Int Immunopharmacol. 2010; 10(7):827-8.

82. Amadu V., Satta R., Montesu M.A., Cottoni F. Kaposi's sarcoma associated with treatment with adalimumab. Dermatol Ther. 2012; 25(6):619-20.

83. Pantanowitz L., Fruh K., Marconi S., Moses A.V., Dezube B.J. Pathology of rituximab-induced Kaposi sarcoma flare. BMC Clin Pathol. 2008; 8:7.

84. Martinez-Martinez M.L., Perez-Garcia L.J., Escario-Travesedo E., Ribera-Vaquerizo P.A. [Kaposi sarcoma associated with infliximab treatment]. Actas Dermosifiliogr. 2010; 101(5):462-4.

85. Kim S.Y., Solomon D.H. Tumor necrosis factor blockade and the risk of viral infection. Nat Rev Rheumatol. 2010; 6(3):165-74.

86. Handisurya A., Schellenbacher C., Kirnbauer R. Diseases caused by human papillomaviruses (HPV). J Dtsch Dermatol Ges. 2009; 7(5):453-66; quiz 66, 67.

87. Gravitt P.E. Evidence and impact of human papillomavirus latency. Open Virol J. 2012; 6:198-203.

88. Maglennon G.A., Doorbar J. The biology of papillomavirus latency. Open Virol J. 2012; 6:190-7.

89. Waisberg M.G., Ribeiro A.C., Candido W.M., Medeiros P.B., Matsuzaki C.N., Beldi M.C., et al. Human papillomavirus and chlamydia trachomatis infections in rheumatoid arthritis under anti-TNF therapy: an observational study. Rheumatol Int. 2015; 35(3):459-63

90. Georgala S., Katoulis A.C., Kanelleas A., Befon A., Georgala C. Letter: Human papilloma virus and molluscum contagiosum lesions related to infliximab therapy for psoriasis: a case series. Dermatol Online J. 2012; 18(4):9.

91. Duiculescu D., L E. Leucoencefalita multifocală progresivă (PML). Ro J Infect Dis. 2006; 9:40-50.

92. Wiedinger K., Bitsaktsis C., Chang S. Reactivation of human polyomaviruses in immunocompromised states. J Neurovirol. 2014; 20(1):1-8.

93. Delbue S., Ferraresso M., Ghio L., Carloni C., Carluccio S., Belingheri M., et al. A review on JC virus infection in kidney transplant recipients. Clin Dev Immunol. 2013; 2013:926391.

94. Costa C., Cavallo R. Polyomavirus-associated nephropathy. World J Transplant. 2012; 2(6):84-94.
95. White M.K., Khalili K. Pathogenesis of progressive multifocal leukoencephalopathy - revisited. J Infect Dis. 2011; 203(5):578-86.

96. Tan C.S., Ellis L.C., Wuthrich C., Ngo L., Broge T.A., Jr., SaintAubyn J., et al. JC virus latency in the brain and extraneural organs of patients with and without progressive multifocal leukoencephalopathy. J Virol. 2010; 84(18):9200-9.

97. Tan C.S., Dezube B.J., Bhargava P., Autissier P., Wuthrich C., Miller J., et al. Detection of JC virus DNA and proteins in the bone marrow of HIV-positive and HIV-negative patients: implications for viral latency and neurotropic transformation. J Infect Dis. 2009; 199(6):881-8.

98. Wollebo H.S., Woldemichaele B., Khalili K., Safak M., White M.K. Epigenetic regulation of polyomavirus JC. Virol J. 2013; 10:264.

99. Chalkley J.J., Berger J.R. Progressive multifocal leukoencephalopathy in multiple sclerosis. Curr Neurol Neurosci Rep. 2013;13(12):408

100.Mosli M., Al Beshir M., Al-Judaibi B., Al-Ameel T., Saleem A., Bessissow T., et al. Advances in the diagnosis and management of inflammatory bowel disease: challenges and uncertainties. Saudi J Gastroenterol. 2014; 20(2):81-101.

101.Schwab N., Ulzheimer J.C., Fox R.J., Schneider-Hohendorf T. Kieseier B.C., Monoranu C.M., et al. Fatal PML associated with efalizumab therapy: insights into integrin alphaLbeta2 in JC virus control. Neurology. 2012; 78(7):458-67; discussion 65.

102. Mok C.C. Rituximab for the treatment of rheumatoid arthritis: an update. Drug Des Devel Ther. 2013; 8:87-100.

103.Molloy E.S., Calabrese L.H. Progressive multifocal leukoencephalopathy associated with immunosuppressive therapy in rheumatic diseases: evolving role of biologic therapies. Arthritis Rheum. 2012; 64(9):3043-51.

104.Bharat A., Xie F., Baddley J.W., Beukelman T., Chen L., Calabrese L., et al. Incidence and risk factors for progressive multifocal leukoencephalopathy among patients with selected rheumatic diseases. Arthritis Care Res (Hoboken). 2012; 64(4):612-5

105.Fleischmann R.M. Progressive multifocal leukoencephalopathy following rituximab treatment in a patient with rheumatoid arthritis. Arthritis Rheum. 2009; 60(11):3225-8.

106.Clifford D.B., Ances B., Costello C., Rosen-Schmidt S., Andersson M., Parks D., et al. Rituximab-associated progressive multifocal leukoencephalopathy in rheumatoid arthritis. Arch Neurol. 2011; 68(9):1156-64.

107.Kobayashi K., Okamoto Y., Inoue H., Usui T., Ihara M., Kawamata J., et al. Leukoencephalopathy with cognitive impairment following tocilizumab for the treatment of rheumatoid arthritis (RA). Intern Med. 2009; 48(15):1307-9.

108.Fidder H., Schnitzler F., Ferrante M., Noman M., Katsanos K., Segaert S., et al. Long-term safety of infliximab for the treatment of inflammatory bowel disease: a single-centre cohort study. Gut. 2009; 58(4):501-8.

109. Yamamoto M., Takahashi H., Wakasugi H., Sukawa Y., Saito M., Suzuki C., et al. Leukoencephalopathy during administration of etanercept for refractory rheumatoid arthritis. Mod Rheumatol. 2007; 17(1):72-4.

110.Keyser F.D. Choice of Biologic Therapy for Patients with Rheumatoid Arthritis: The Infection Perspective. Curr Rheumatol Rev. 2011; 7(1):77-87. 